This is the last draft sent to the Editorial by the authors of the article:

S. F. MEDINA, M. GÓMEZ, J. I. CHAVES, P. P. GÓMEZ, P. ADEVA "Study on ferrite intragranular nucleation in a V-microalloyed steel"

Materials Science Forum

Vol. 500-501 (2005), Pages: 371-378

DOI: 10.4028/www.scientific.net/MSF.500-501.371

ISSN: 0255-5476

To be published in Digital.CSIC, the Institutional Repository of the Spanish National Research Council (CSIC)

See more papers from the authors on:

$\underline{\text { http://digital.csic.es }}$

http://www.researcherid.com/rid/B-7922-2008 


\title{
Study on Ferrite Intragranular Nucleation in a V-Microalloyed Steel
}

\author{
S.F. Medina ${ }^{1}$, M. Gómez ${ }^{1}$, J.I. Chaves ${ }^{1}$, P.P. Gómez ${ }^{1}$ and P. Adeva ${ }^{1}$ \\ ${ }^{1}$ National Centre for Metallurgical Research (CENIM-CSIC) \\ Av. Gregorio del Amo 8; 28040-Madrid (Spain) \\ E-mail: smedina@cenim.csic.es
}

Keywords: VN-particles, ferrite intragranular nucleation, grain size, RPTT diagrams.

\begin{abstract}
The intragranular nucleation of ferrite has been studied in a V-microalloyed steel $(\mathrm{C}=0.102 ; \mathrm{Mn}=1.479 ; \mathrm{V}=0.140 ; \mathrm{N}=0.016$, \%wt). By means of hot torsion tests, recrystallization-precipitation-time-temperature (RPTT) diagrams have been drawn which show the precipitation kinetics and the recrystallization-precipitation interaction at any temperature. RPTT diagrams were determined at two strains, 0.20 and 0.35 respectively. Deformation tests were carried out at $890^{\circ} \mathrm{C}$ and different holding times, corresponding to moments before the start of precipitation, during precipitation and after precipitation had ended, respectively. In order to relate the precipitation state with the intragranular nucleation, the strengthening of austenite was measured taking into account the non-recrystallized austenite fraction prior to the phase transformation. In this way, the possibility of V-nitrides acting as nucleation sites was evaluated by comparison of ferrite grain size versus holding time. Thus it was found that the precipitate size and precipitated volume are influencing the intragranular nucleation, although this is not a strong influence.
\end{abstract}

\section{Introduction}

It is important to produce many variants locally for the effective refinement of microstructures that improves the mechanical properties of steel and others alloys [1].

The intragranular nucleation of ferrite in a recrystallized or a fully or partially deformed austenite has become one of the most recent study areas in the field of steels, with the objective of increasing the possibilities offered by several types of precipitates or inclusions to become nucleation sites. In this way, in addition to the sites known as classic sources of the heterogeneous nucleation of ferrite, such as grain boundaries and dislocations, there would be a third way of contributing to refining the ferrite grain.

Some authors [2-4] have studied the intragranular nucleation of idiomorphic ferrite on incoherent complex precipitates formed by MnS inclusions and $\mathrm{V}(\mathrm{C}, \mathrm{N})$ precipitates. Others $[5,6]$ have studied the intragranular nucleation of acicular ferrite on $\mathrm{Ti}_{2} \mathrm{O}_{3}$ particles, or also on mixed inclusions of MnS-CuS [7]. In general, these particles have proven to be efficient as nucleation sites for ferrite and attention has been drawn to the important role played by SMn inclusions, even when they seem to be associated to $\mathrm{Ti}_{2} \mathrm{O}_{3}$ particles [8].

Several reasons have been proposed to justify the efficiency of these particles. On the one hand the formation of MnS produces a local Mn impoverishment which favours the nucleation of ferrite. On the other hand, VC or VN has a low interfacial energy with respect to ferrite but a relatively high interfacial energy with respect to austenite for the $(001)_{\mathrm{V}(\mathrm{C}, \mathrm{N})}$ boundary compared with MnS. These advantages of VC and VN over MnS in the balance of interphase boundary energy presumably promote the intragranular ferrite transformation for the complex precipitates [9].

The present work has studied intragranular nucleation in a steel containing $\mathrm{V}$ as microalloying element using a different methodology, where it possible to know the precipitation state and the deformation state prior to the start of the ferrite transformation. In this way it has been intended to 
distinguish between intragranular nucleation on precipitates and that which takes place on other defects such as dislocations or subgrains.

\section{Materials and Experimental Procedure}

A steel $(0.102 \% \mathrm{C}, 1.479 \% \mathrm{Mn}, 0.140 \% \mathrm{~V}, 0.016 \% \mathrm{~N}, 0.005 \% \mathrm{~S}$, in wt\%) was manufactured in industrial conditions. This is a low carbon steel microalloyed with $\mathrm{V}$ and a low $\mathrm{S}$ content.

Torsion specimens were prepared with a gauge length of $50 \mathrm{~mm}$ and diameter of $6 \mathrm{~mm}$. The reheating temperature before torsion deformation was $1200^{\circ} \mathrm{C}$, above the solubility temperature of nitrides, carbides or carbonitrides, and the holding time was $10 \mathrm{~min}$. The testing temperatures varied between $1100^{\circ} \mathrm{C}$ and $800^{\circ} \mathrm{C}$. The steel was tested at strains of 0.20 and 0.35 . The recrystallized fraction was determined using the "back extrapolation" method [10]. With the aim of revealing the possible intragranular ferrite nucleation on V-precipitates, a further microscopy study, using a Jeol JSM 6500F scanning electron microscope equipped with a field emission gun (SEM-FEG), was carried out.

\section{Results and Discussion}

Static Recrystallization. The solubility temperatures for nitrides and carbides were calculated according to Turkdogan's solubility product [11]. The reheating temperature applied to the steel was $1200^{\circ} \mathrm{Cx} 10$ min which was enough to put into solution all the V-carbonitrides. The austenite grain size at the reheating temperature was determined by quenching of the specimen. Table 1 shows the calculated solubility temperatures and the austenite grain size obtained.

Table 1. Solubility temperature of the precipitates and austenite grain size for the steel used.

\begin{tabular}{|c|c|c|c|}
\hline \multicolumn{2}{|c|}{ Solubility Temperature, $\mathrm{T}_{\mathrm{s}}\left({ }^{\circ} \mathrm{C}\right)$} & $\begin{array}{c}\text { Average Diameter, } \\
\bar{d}(\mu \mathrm{m})\end{array}$ & $\begin{array}{c}\text { Mean Intercept, } \\
\bar{l}(\mu \mathrm{m})\end{array}$ \\
\hline 812 & 1124 & 82.6 & 73.6 \\
\hline
\end{tabular}

The recrystallized fraction was determined at different temperatures, at equivalent strains of 0.20 and 0.35 , at a constant strain rate of $3.63 \mathrm{~s}^{-1}(1000 \mathrm{rev} / \mathrm{min})$. The specimens were reheated at a sufficient temperature $\left(1200^{\circ} \mathrm{Cx} 10 \mathrm{~min}\right)$ to dissolve the precipitates, after which the temperature was rapidly reduced to that corresponding to the deformation. A scheme similar to that shown in Fig. 1 was followed.

The recrystallized fraction, determined by applying the back extrapolation method, was drawn against time for each testing temperature (Figs. 2 and 3) at strains of 0.20 and 0.35, respectively. It is observed that some curves display a plateau caused by the formation of precipitates which momentarily inhibit the progress of recrystallization. The start and finish of the plateau are identified approximately with the start and finish of the induced precipitation.

The curves corresponding to temperatures above those showing plateaus have the sigmoidal shape of Avrami's law. Furthermore, in the curves that show a plateau the latter is not unlimited, i.e. precipitation does not permanently inhibit recrystallization and recrystallization progresses again until it is complete, following a graphic plot similar to that recorded before the formation of the plateau.

The comparison of curves corresponding to the same temperature and different strains clearly shows that the recrystallization kinetics are faster for the strain of 0.35 , as was to be expected. 


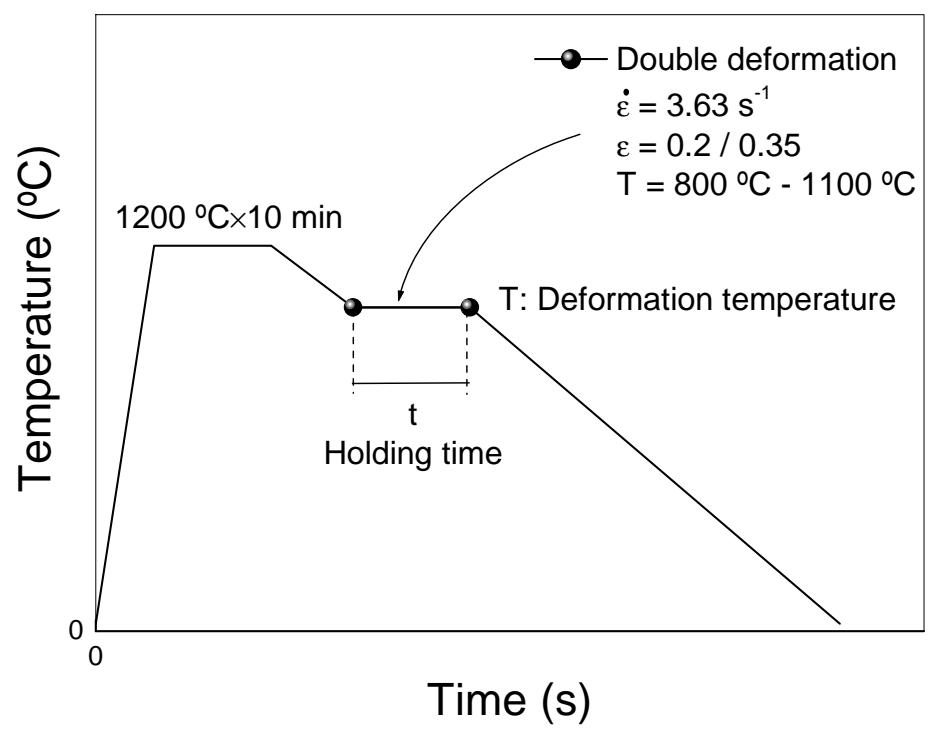

Fig. 1. Double deformation tests.

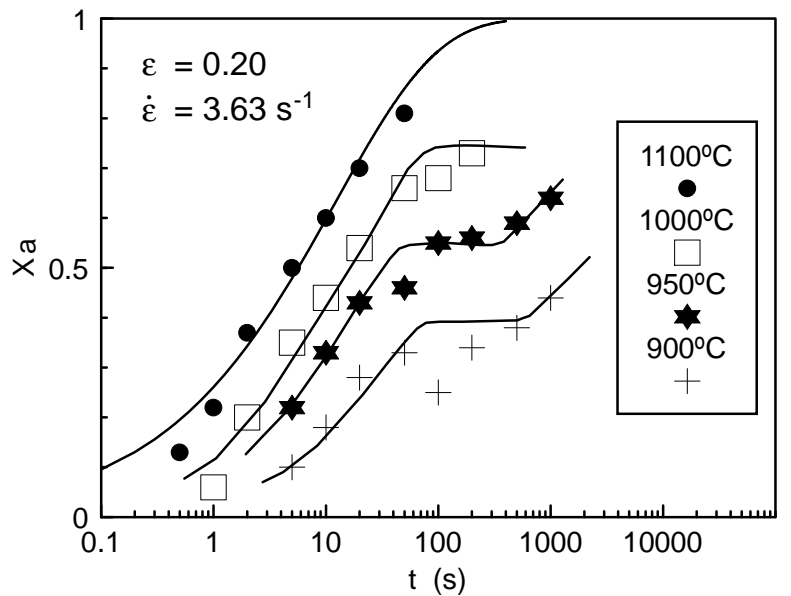

Fig. 2. Variation in the recrystallized fraction $\left(\mathrm{X}_{\mathrm{a}}\right)$ with the time $t$ for the steel used. $\varepsilon=0.20$.

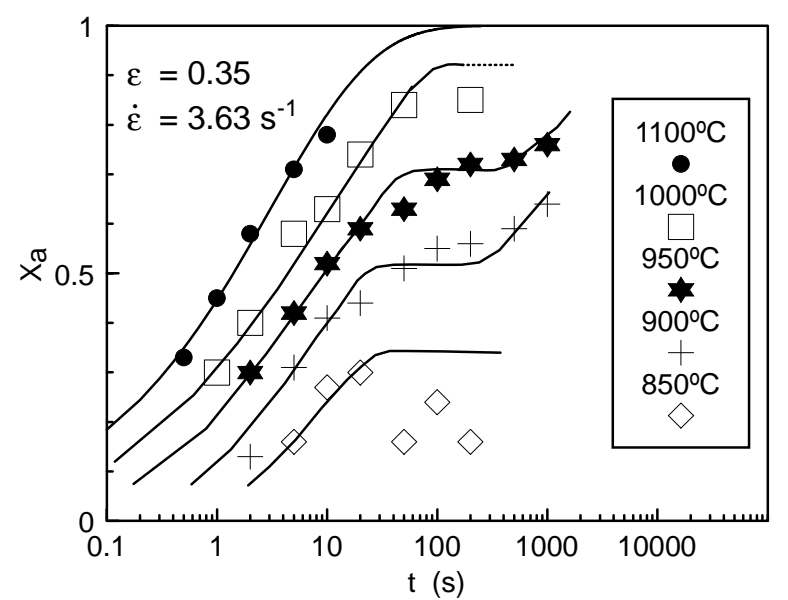

Fig. 3. Variation in the recrystallized fraction $\left(\mathrm{X}_{\mathrm{a}}\right)$ with the time $\mathrm{t}$ for the steel used. $\varepsilon=0.35$

RPTT Diagrams. Recrystallized fraction curves can be used to plot recrystallization-precipitation-time-temperature (RPTT) diagrams. The points that define the start and end of the plateau were taken to plot the induced precipitation start $\left(\mathrm{P}_{\mathrm{s}}\right)$ and finish $\left(\mathrm{P}_{\mathrm{f}}\right)$ curves, respectively. The temperatures and times corresponding to different recrystallized fractions, such as 0.3, 0.5, 0.7 and 0.9, were also deduced from recrystallized fraction curves. In this way we have drawn the RPTT diagrams, of which Figs. 4 and 5 are two examples, corresponding to strains of 0.20 and 0.35 , respectively. Note that the recrystallized fraction does not vary between the precipitation start $\left(\mathrm{P}_{\mathrm{s}}\right)$ and finish $\left(\mathrm{P}_{\mathrm{f}}\right)$ curves and is represented by a horizontal line. Once the $\mathrm{P}_{\mathrm{f}}$ curve is reached, the lines of each recrystallized fraction descend, meaning that as the temperature drops more time is necessary to obtain a certain recrystallized fraction after straining.

With regard to the recrystallization-precipitation interaction, it is seen that at the nose of the $\mathrm{P}_{\mathrm{s}}$ curve, where the precipitate incubation time $\left(\mathrm{t}_{\mathrm{N}}\right)$ is minimal, the recrystallized volume fraction is approximately $50 \%$. When the recrystallized volume fraction is less than $20 \%$, nucleation of the precipitates is very 
difficult. In other words, for nucleation to be possible it is necessary for the recrystallized fraction to be equal to or greater than $20 \%$.

At the instant that precipitation starts, which coincides approximately with the $\mathrm{P}_{\mathrm{s}}$ curve, whatever the deformation temperature, the precipitated volume percentage is assumed to be less than or close to $10 \%$. When the $\mathrm{P}_{\mathrm{f}}$ curve is reached it is assumed that precipitation has ended, though this is not yet sufficiently demonstrated. It is known that once the plateau has ended, and consequently recrystallization is progressing, the pinning forces exerted by the precipitates are now lower than the driving forces of recrystallization. However, recent studies have demonstrated that at the end of the plateau a small fraction of precipitates conserve the same size as the precipitates formed at the start of precipitation. Therefore, this suggests that the end of the plateau, or the $\mathrm{P}_{\mathrm{f}}$ curve, coincides approximately with the end of the precipitation kinetics [12].

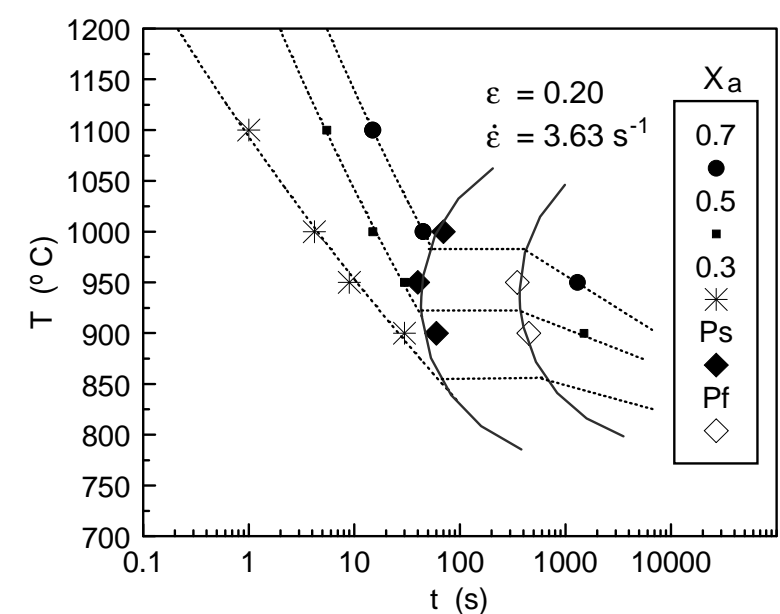

Fig. 4. RPTT diagram for the steel used. $\varepsilon=0.20$.

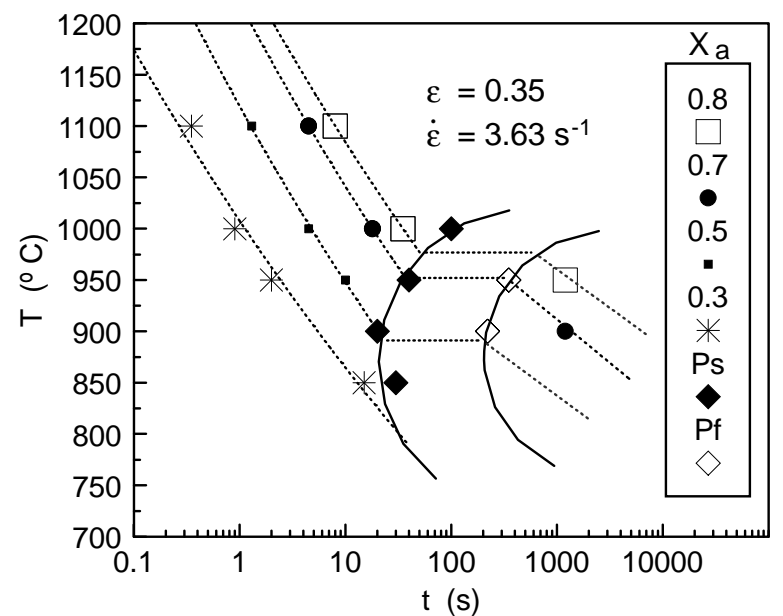

Fig. 5. RPTT diagram for the steel used. $\varepsilon=0.35$.

The RPTT diagrams, and especially the $\mathrm{P}_{\mathrm{s}}$ and $\mathrm{P}_{\mathrm{f}}$ curves, define a time interval, whatever the temperature, during which the precipitation state (size and precipitated volume) is changing. At the start $\left(\mathrm{P}_{\mathrm{s}}\right.$ curve) the average precipitate size is just a few nanometres $(<15 \mathrm{~nm})$ and at the end $\left(\mathrm{P}_{\mathrm{f}}\right.$ curve) can reach a size of more than $100 \mathrm{~nm}$. For times after $\mathrm{P}_{\mathrm{f}}$, the precipitated volume does not vary but a coarsening of the precipitates occurs due to the effect of Ostwald ripening [12].

Ferrite Microstructures and Grain Size. With the aim of studying the intragranular nucleation of the ferrite by heterogeneous nucleation on the precipitates, specimens of the steel used were deformed and held for a certain time, according to the RPTT diagrams. The deformation conditions (strain, temperature, holding time) were selected in such a way as to approximately coincide with the curve nose temperature, with the precipitation start and end times, previously applying the strain in accordance with the RPTT diagrams. After the holding time the specimens were cooled with argon at a cooling rate $(\mathrm{dT} / \mathrm{dt})_{800-500^{\circ} \mathrm{C}}$ of approximately $5 \mathrm{~K} / \mathrm{s}$. The testing conditions are shown in Table 2 , having selected holding times at the deformation temperature before the start of precipitation, close to the start, at the end of precipitation, and after the precipitation has finished, respectively. This table also indicates the recrystallized fraction corresponding to the austenite before the start of the austenite $\rightarrow$ ferrite transformation.

The metallographic study allowed the ferrite grain sizes to be measured applying the linear intersection method (Table 2). Fig. 6 illustrates the change in the ferrite grain with the precipitation time at strains of 0.20 and 0.35 , respectively, and a reduction in the grain size with precipitation time is in general appreciated. 
Table 2. Hot deformation conditions. Reheating temperature: $1200^{\circ} \mathrm{Cx} 10 \mathrm{~min}$.

\begin{tabular}{|c|c|c|c|c|}
\hline Def. Temp., ${ }^{\circ} \mathrm{C}$ & Strain $(\varepsilon)$ & $\begin{array}{c}\text { Holding } \\
\text { time, } \mathrm{s}\end{array}$ & $\begin{array}{c}\text { Austenite } \\
\text { recrystallized } \\
\text { fraction }, \mathrm{X}_{\mathrm{a}}\end{array}$ & $\begin{array}{c}\text { Ferrite grain } \\
\text { size, } \mu \mathrm{m}\end{array}$ \\
\hline \multirow{3}{*}{900} & \multirow{3}{*}{0.20} & 5 & 0.10 & 25.6 \\
\cline { 3 - 5 } & & 20 & 0.28 & 20.5 \\
\cline { 3 - 5 } & & 40 & 0.33 & 16.6 \\
\cline { 3 - 5 } & & 400 & 0.38 & 13.8 \\
\hline \multirow{3}{*}{890} & \multirow{3}{*}{0.35} & 5 & 0.44 & 15 \\
\hline & & 15 & 0.30 & 20.2 \\
\cline { 3 - 5 } & & 35 & 0.43 & 15.5 \\
\cline { 3 - 5 } & & 200 & 0.50 & 15.5 \\
\cline { 3 - 5 } & & 300 & 0.51 & 13.5 \\
\hline
\end{tabular}

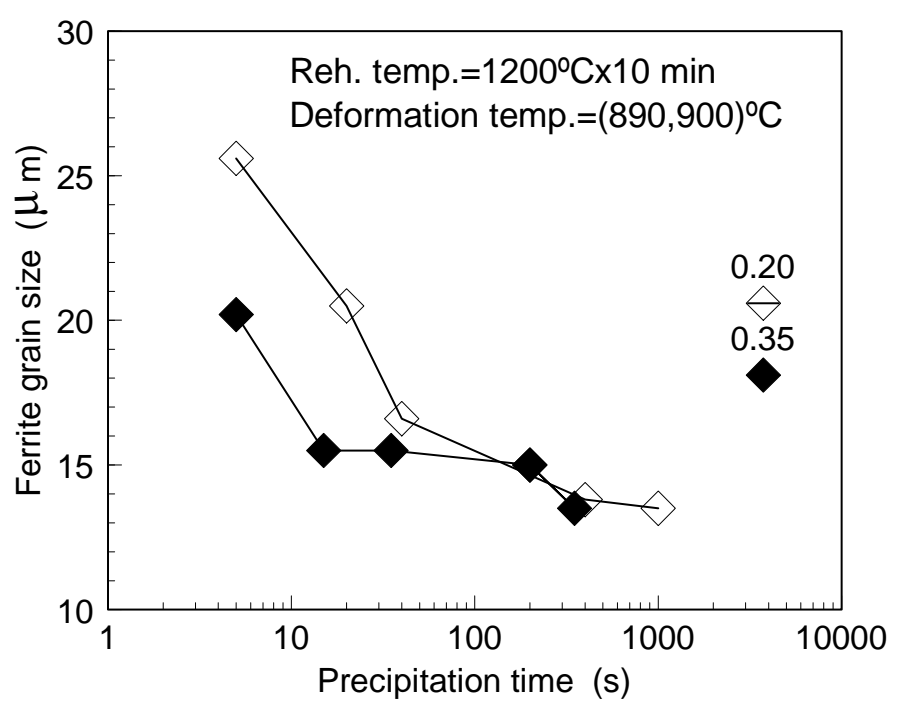

Fig. 6. Ferrite grain size against precipitation time.

The reduction in grain size is more effective when the strain was 0.20 . On the one hand, the times of 5 and 20 s correspond to moments before the start of precipitation and therefore the reduction in the ferrite grain size must be due to the strong reduction in the austenite grain size because of the increase in the recrystallized fraction. Between the times of 40 and $400 \mathrm{~s}$, which correspond approximately to the start and the end of precipitation, a notable decrease is seen in the ferrite grain size and this is presumably due to the fact that the intragranular nucleation of the ferrite on vanadium precipitates has taken place to a certain extent.

When the applied strain was 0.35 , the possible intragranular nucleation of the austenite is not clear, since between the start and end of precipitation hardly any reduction is seen in the ferrite grain size. It is highly possible that the increase in the strain, which in turn increases the density of dislocations, decreases the possibilities for intragranular nucleation to take place in the volume not yet recrystallized and that at the times corresponding to the start and end of precipitation it is still 50\%. Finally, Figs. 7 and 8 show two microstructures each, referring to different holding times after the deformation. 


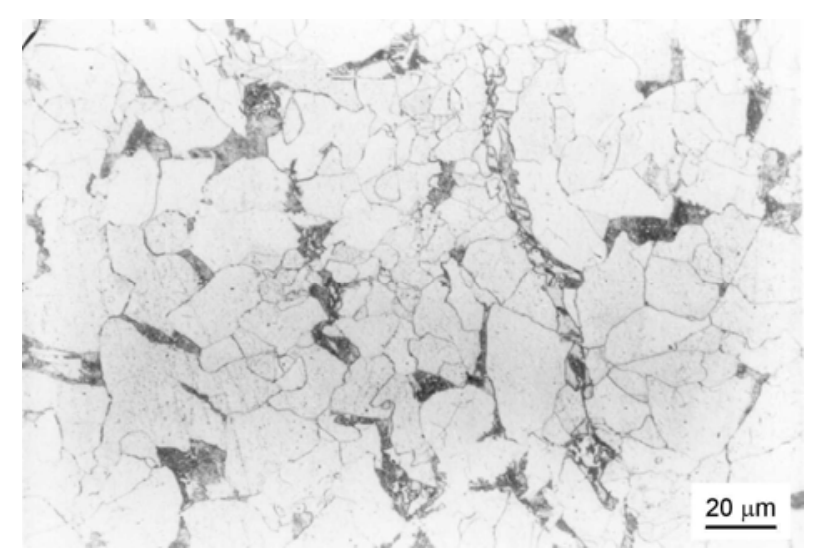

(a)

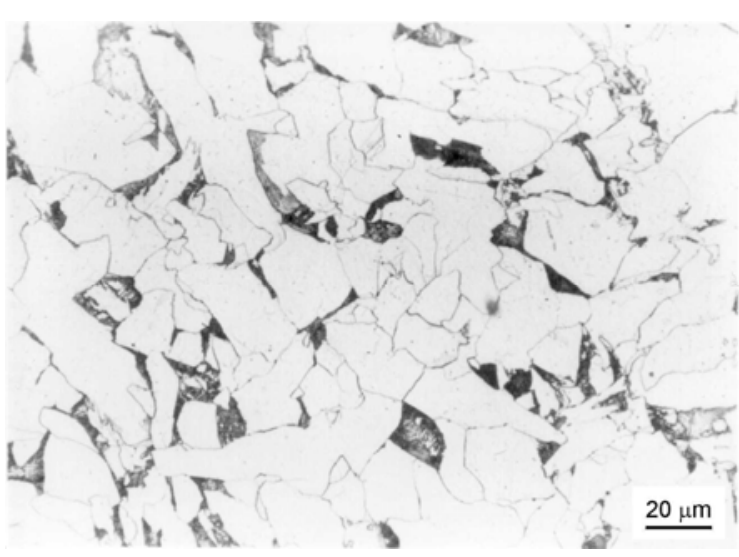

(b)

Fig. 7. Ferrite microstructures at deformation temperature of $900^{\circ} \mathrm{C}$ and strain of 0.20. (a) holding time $=20 \mathrm{~s}$; (b) holding time $=400 \mathrm{~s}$

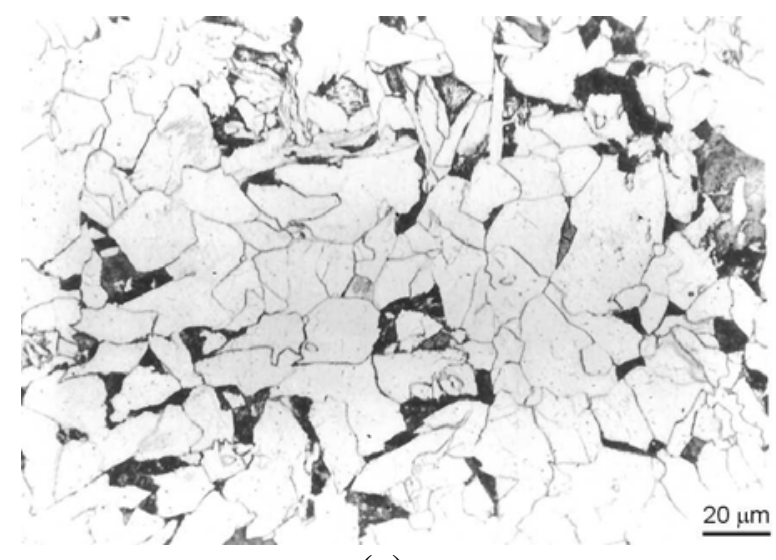

(a)

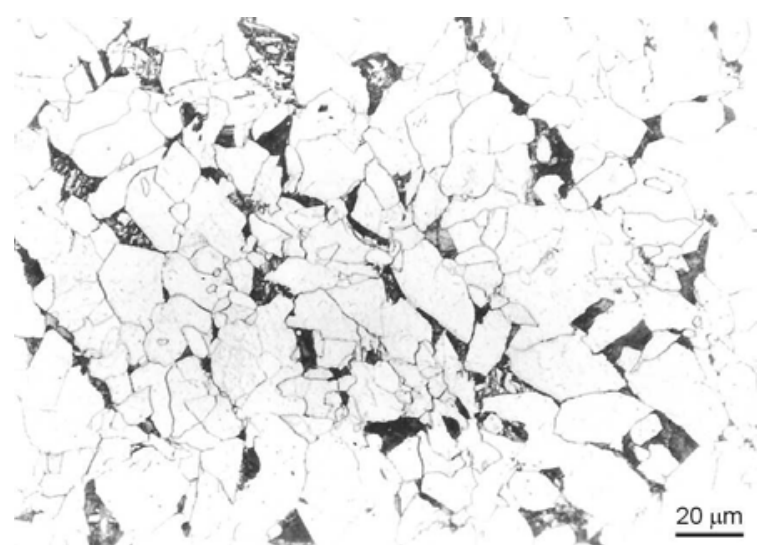

(b)

Fig. 8. Ferrite microstructures at deformation temperature of $890^{\circ} \mathrm{C}$ and strain of 0.35. (a) holding time $=35 \mathrm{~s}$; (b) holding time $=350 \mathrm{~s}$

Microstructural Study by Scanning Electron Microscopy (SEM-FEG). With the aim of revealing the possible intragranular ferrite nucleation on V-precipitates, a further microscopy study, using a scanning electron microscope equipped with a field emission gun (SEM-FEG), was carried out.

Fig. 9(a) shows a small ferrite grain with a precipitate on a grain boundary. This grain boundary precipitate can be better observed in Fig. 9(b) and Fig. 10(a) at higher magnifications. Finally, on the spectrum of Fig. 10(b) the peaks corresponding to vanadium can be found.

Previous images seem to reveal that the V-precipitate has acted as a nucleation site for the small ferrite grain. The observation of several images made it possible to verify the presence of many small ferritic grains in this sample as well as in others of the steel used, tested in different conditions and with longer precipitation times, corresponding to higher precipitated volumes and coarser precipitate sizes.

Finally, it is interesting to note that the spectrum does not indicate the presence of $S$, in the same way as in other analyses. 


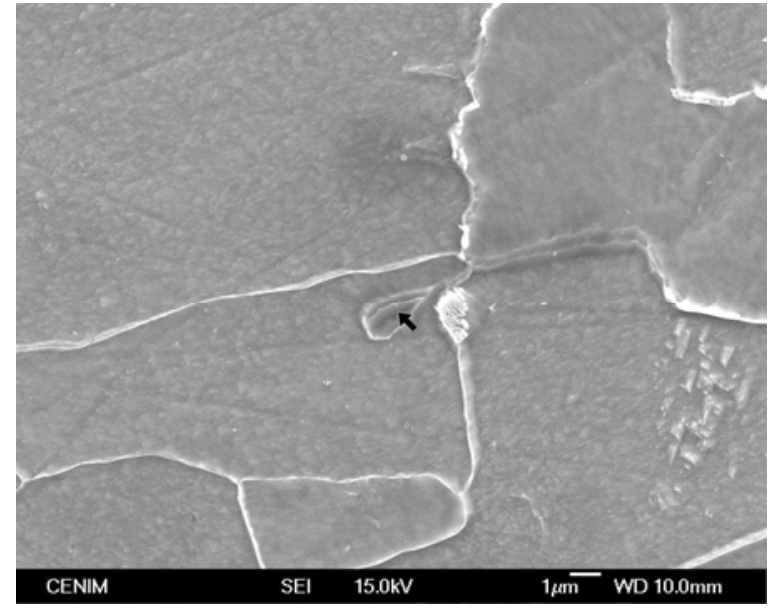

(a)

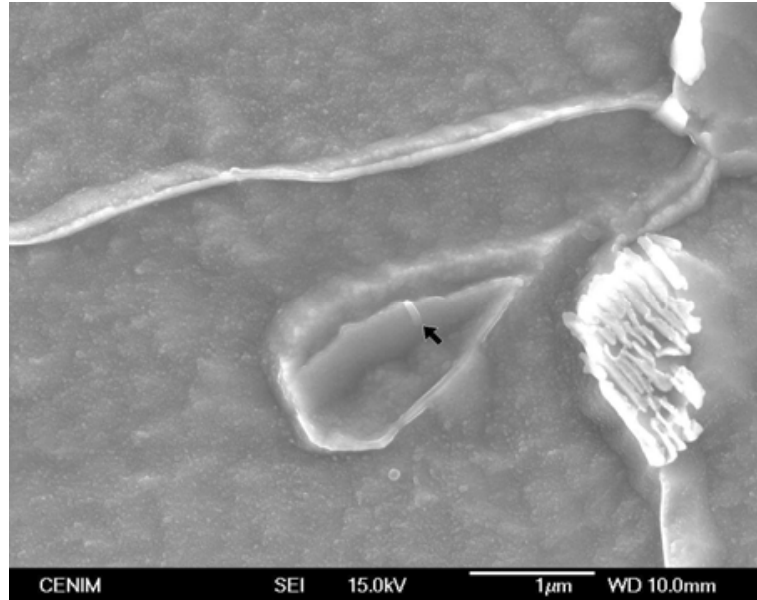

(b)

Fig. 9. SEM-FEG images at different magnifications showing ferrite small grains and a precipitate indicated by the arrow: Reh. Temp. $=1200^{\circ} \mathrm{Cx} 10 \mathrm{~min}$; Def. temp. $=890^{\circ} \mathrm{C} ; \varepsilon=0.35$; Holding time $=35 \mathrm{~s}$.

(a)

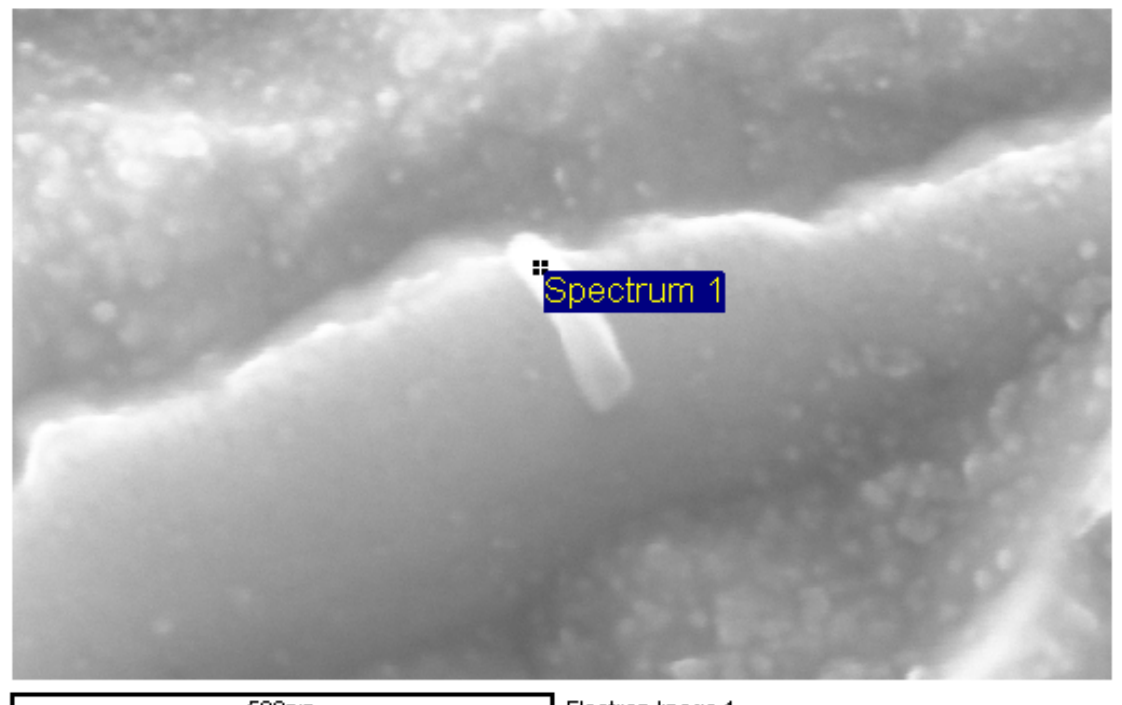

$500 n m$

Electron Image

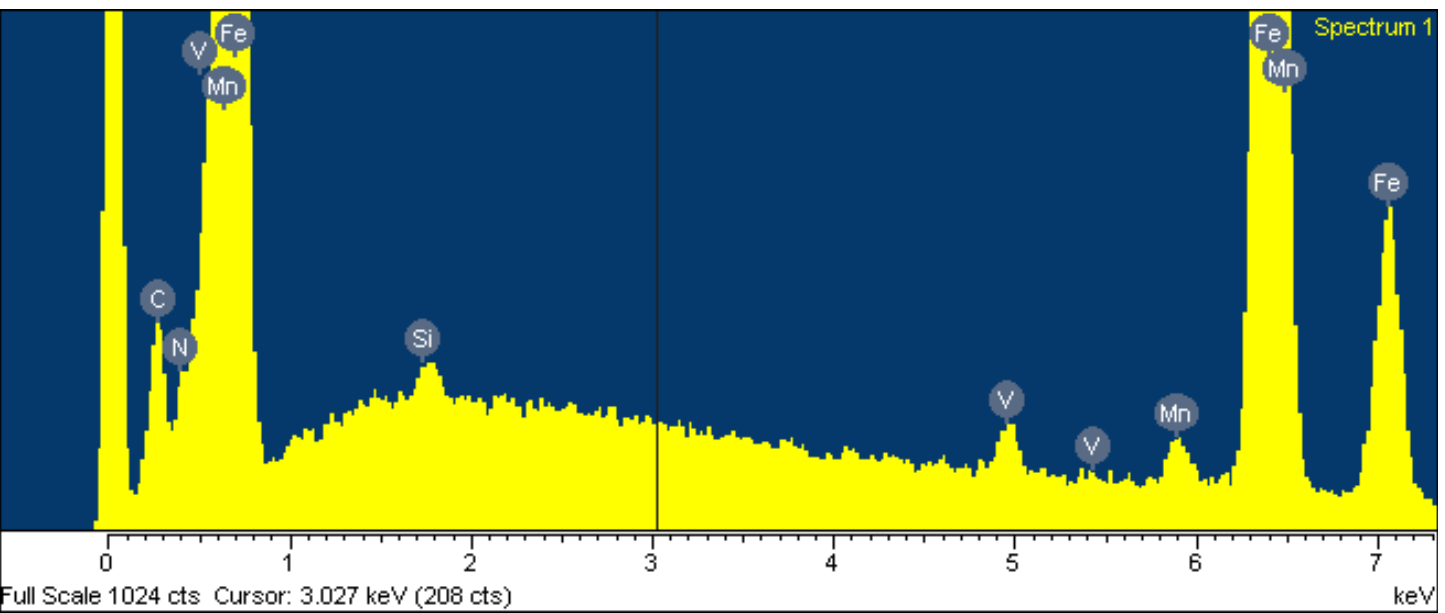

Fig. 10. SEM-FEG image. (a) Same precipitate as in Fig. 9. (b) Spectrum of V-precipitate. 


\section{Conclusions}

1. The nucleation of the ferrite on austenite grain boundaries is more important than the contribution of the increase in the density of dislocations and the precipitated volume, respectively.

2. For the same austenite grain size and recrystallized fraction (same density of dislocations), intragranular nucleation is more effective when the non-recrystallized fraction is less strengthened.

3. The conventional measurement of the ferritic grain size is not the most suitable for revealing intragranular nucleation, since many of the small grains, of the order of 1-2 microns, with precipitates in their interior, are difficult to evaluate.

\section{Acknowledgment}

Financial support of this work by the ECSC (Project 7210-PR/289) is gratefully acknowledged.

\section{References}

[1] T. Furuhara, T. Maki: Mat. Sci. Eng. A-Struct. Vol. 312 (2001), p. 145.

[2] T. Furuhara, T. Shinyoshi, G. Miyamoto, J. Yamaguchi, N. Sugita, N. Kimura, N. Takemura, T. Maki: ISIJ Int. Vol. 43 (2003), p. 2028.

[3] G. Miyamoto, T. Shinyoshi, J. Yamaguchi, T. Furuhara, T. Maki, U. Uemori: Scripta Mater. Vol. 48 (2003), p. 371.

[4] T. Yokomizo, M. Enomoto, O. Umezawa, G. Spanos, R.O. Rosenberg, Mat. Sci. Eng. A Vol. 344 (2003), p. 261.

[5] J.H. Shim, Y.W. Cho, S.H. Chung, J.D. Shim, D.N. Lee: Acta Mater. Vol. 47 (1999), p. 2751.

[6] J.S. Byun, J.H. Shim, Y.W. Cho, D.N. Lee: Acta Mater. Vol. 51 (2003), p. 1593

[7] I. Madariaga, I. Gutiérrez: Acta Mater. Vol. 47 (1999), p. 951.

[8] J.H. Shim, Y.J. Oh, J.Y. Such, Y.W. Cho, J.D. Shim, J.S. Byun, D.N. Lee: Acta Mater. Vol. 49 (2001), p. 2115.

[9] T. Furuhara, J. Yamaguchi, N. Sugita, G. Miyamoto, T. Maki: ISIJ Int. Vol. 43 (2003), p. 1630.

[10] S.F. Medina, A. Quispe: Mater. Sci. Forum Vols. 426-432 (2003), p. 1139.

[11] E.T. Turkdogan: Iron \& Steelmaker Vol. 16 (1989), p. 61.

[12] S.F. Medina, A. Quispe, P. Valles and J.L. Baños: ISIJ Int., Vol. 39 (1999), p. 913. 